\title{
СУДЕБНАЯ МЕДИЦИНА
}

УДК 340.6

\section{Ятрогенные преступления, совершаемые в сфере здравоохранения, и особый подход к судебно-медицинским экспертным исследованиям}

\author{
С. В. Кузнец,ов \\ Следственное управление Следственного комитета \\ Российской Федерации по Ленинградской области, \\ Российская Федерация, 197342, Санкт-Петербург, Торжковская ул., 4; \\ Санкт-Петербургский государственный аграрный университет, \\ Российская Федерация, 196601, Санкт-Петербург, Петербургское шоссе, 2
}

Для цитирования: Кузнецов С. В. Ятрогенные преступления, совершаемые в сфере здравоохранения, и особый подход к судебно-медицинским экспертным исследованиям // Вестник Санкт-Петербургского университета. Медицина. 2018. Т. 13. Вып. 4. С. 419-429. https://doi. org/10.21638/11701/spbu11.2018.408

Излагается интегрированный подход к судебно-медицинской оценке фактов ненадлежащего оказания медицинской помощи. Целью инициативных положений является повышение эффективности судебно-медицинских экспертиз оказания медицинской помощи, как в структуре Следственного комитета Российской Федерации, так и в иных судебно-экспертных учреждениях, в том числе государственных. Как один из возможных путей решения указанной проблемы приводятся авторские порядок и алгоритм методики производства судебно-медицинских экспертных исследований по ятрогенным преступлениям. Предложены возможные пути совершенствования организации судебно-экспертной деятельности. Обосновано, почему в Следственном комитете РФ предпочитают принимать на службу экспертов широкого профиля (обладающих компетенцией в двух и более смежных областях), которые могут работать по нескольким направлениям. Показано, что такие сотрудники способны комплексно осмыслять медико-биологические проблемы, исходя из конкретной следственной задачи. Данный подход успешно используется на практике в экспертно-криминалистическом отделе управления криминалистики Главного следственного управления Следственного комитета РФ по городу Санкт-Петербургу и в отделе криминалистики следственного управления Следственного комитета РФ по Ленинградской области.

Ключевые слова: судебно-медицинская экспертиза, недостатки оказания медицинской помощи, дефекты медицинской помощи, причинно-следственные связи, вред здоровью.

(C) Санкт-Петербургский государственный университет, 2018 


\section{Введение}

На сегодняшний день в уголовном судопроизводстве в отношении профессиональных деяний медицинских работников, сопровождающихся так называемыми «врачебными» ошибками, применяются составы преступлений, предусмотренные следующими статьями Уголовного кодекса Российской Федерации от 13 июня 1996 года № 63-Ф3 (далее - УК РФ): ч. 2 ст. 109; ч. 2 ст. 118; ст. 124; ст. 125; ст. 293 (для медицинских работников, являющихся должностными лицами); п. «б» и «в» ч. 2, ч. 3, а также ч. 1 ст. 238.

Главное следственное управление Следственного комитета Российской Федерации по городу Санкт-Петербургу (далее - ГСУ СК РФ по г. СПб) и следственное управление Следственного комитета Российской Федерации Ленинградской области (далее - СУ СК РФ по ЛО) имеет опыт более чем четырехлетней работы по экспертному сопровождению собственными силами расследования уголовных дел и проведения доследственных проверок по фактам ненадлежащих профессиональных деяний медицинских работников [1].

Чаще всего специалистов медико-биологического судебно-экспертного профиля используют в следующих формах:

1) рецензирование собственными специалистами ГСУ СК РФ по г. СПб и СУ СК РФ по ЛО заключений ранее проведенных судебно-медицинских экспертиз;

2) участие собственных специалистов при осмотре медицинских документов и предметов с дачей необходимых пояснений;

3) допрос врачей с участием собственного специалиста;

4) допрос с участием собственного специалиста участников экспертной комиссии ранее проведенного судебно-медицинского экспертного исследования;

5) допрос собственного специалиста с учетом ответственности, предусмотренной ст. 307 УК РФ;

6) производство комиссионных судебно-медицинских экспертиз и исследований.

Что касается первых пяти пунктов, то можно констатировать, что данные следственные и иные процессуальные действия в большинстве своем являются подготовительными, в том смысле, что определяют целесообразность, необходимость и возможность производства судебно-медицинской экспертизы оказания медицинской помощи собственными экспертными силами ГСУ СК РФ по г. СПб и СУ СК РФ по ЛО.

\section{Порядок производства судебно-медицинских экспертных исследований}

Для следователя особую важность при принятии процессуального решения по фактам причинения вреда, связанного с оказанием медицинской помощи, имеет прогноз судебно-следственной перспективы по конкретному уголовному делу или материалу доследственной проверки. Для этого целесообразно каждый случай назначения судебно-медицинской экспертизы собственным судебно-медицинским 
экспертам СК РФ предварять черновым судебно-медицинским анализом. В рамках данного анализа специалистом в области судебной медицины применительно к конкретному случаю ненадлежащего оказания медицинской помощи всесторонне и полно исследуются документы, содержащие медицинские сведения, для оценки признаков обстоятельств, подлежащих доказыванию в соответствии со ст. 73 Уголовно-процессуального кодекса Российской Федерации от 18 декабря 2001 г. № 174ФЗ (далее - УПК РФ).

Результатом вышеуказанного предварительного судебно-медицинского анализа становится официальный письменный процессуальный документ - заключение специалиста в области судебной медицины, выполненный собственным судебно-медицинским экспертом СК РФ. Данное заключение специалиста требует меньшего интеллектуально-волевого участия следователя при назначении судебно-медицинского экспертного исследования, а на выполнение самого исследования затрачивается гораздо меньше времени и экспертных ресурсов. Однако при всем этом такое заключение определяет перспективу соответствующей судебной экспертизы. В определенных таким образом нерезультативных для следствия случаях дальнейшее выполнение судебно-медицинской экспертизы оказания медицинской помощи собственными экспертными силами ГСУ СК РФ по г. СПб и СУ СК РФ по ЛО может и не потребоваться, так как будет достаточно результатов судебно-медицинских экспертных исследований, ранее проведенных во внешних судебно-экспертных учреждениях. В любых других значимых для следствия случаях собственные судебно-медицинские эксперты привлекаются согласно порядку производства судебно-медицинских экспертных исследований, применяемому в ГСУ СК РФ по г. СПб и в СУ СК РФ по ЛО, который включает в себя несколько этапов [2] (далее цитата согласно ссылке).

«1. Предварительный судебно-медицинский анализ предоставленных медицинских документов и объектов с письменным поручением (обязательно включающим сведения о лице и органе, назначившем экспертное исследование; номере уголовного дела или материала проверки; инкриминируемой статье и событии преступного деяния; дате и времени преступления; наименованиях предоставляемых материалов с указанием количества листов медицинских и иных документов; а также данные потерпевших и подозреваемых).

2. Уяснение задачи, поставленной следствием в оригинальной редакции, и экспертный прогноз результатов решения такой задачи.

3. Коммуникация с органом, назначившим экспертное исследование, с целью определения перспективы предлагаемой экспертной инициативы (в случае наличия таковой по результатам 1 и 2 этапов).

4. Исследование имеющихся медицинских сведений посредством их судебномедицинского анализа в одной плоскости понимания с лицом, назначившим судебно-медицинское экспертное исследование, с позиций обстоятельств, подлежащих доказыванию согласно ст. 73 УПК РФ.

5. Судебно-медицинская оценка результатов исследования - обоснование выводов экспертного заключения.

6. Выводы - дача ответов на поставленные вопросы и доведение инициативных положений. 
Пункты 1 и 2 реализуются с помощью чтения экспертом предоставленных материалов (либо надлежащим образом заверенных их копий), пункт 3 - посредством вербального общения эксперта и следователя, пункты 4, 5 и 6 являются «написательными», то есть представляют собой собственно производство экспертного исследования согласно авторскому алгоритму методики производства судебно-медицинских экспертных исследований по ятрогенным преступлениям [3]».

\section{Методика проведения судебно-медицинских экспертных исследований по фактам ятрогенных преступлений}

Упомянутая методика прошла апробацию и показала свою эффективность в течение трехлетнего периода своего применения на значительном количестве материала [4], а также была одобрена и рекомендована к использованию профессиональным сообществом криминалистов, судебных экспертов и юристов [решение собрания № 2 Сообщества Балтийских криминалистов от 17 марта 2017 г.].

Согласно рассматриваемой методике представляется, что ненадлежащее действие (бездействие) медицинских работников следует расценивать как «разновидность причин», которые определяют неизбежность наступления неблагоприятных последствий вплоть до летального исхода. При этом преступление может совершаться как в форме действия (когда речь идет о неадекватных действиях медика), так и в форме бездействия (когда всесторонние меры по улучшению состояния пациента фактически не принимаются) [5].

Под «ненадлежащностью» медицинской деятельности предлагается понимать либо необоснованное, либо несвоевременное, либо технически неправильное, либо необусловленное, либо недостаточное медицинское деяние [6]. Таким образом, «ненадлежащность» подразумевает под собой судебно-медицинский эквивалент юридического понятия «противоправность» профессионального деяния медицинского работника.

Учитывая, что большинство применяемых в отношении медицинских работников составов УК РФ материальные, то есть те, в которых законодатель связывает момент окончания преступления с наступлением общественно опасных последствий, то при расследовании профессиональных медицинских преступлений и проведении доследственных проверок в первую очередь установлению и доказыванию подлежат:

1) факт ненадлежащего оказания медицинской помощи (услуг);

2) вред здоровью в результате оказания (неоказания) медицинской помощи;

3) причинно-следственная связь между п. 1 и 2.

Выяснение указанных обстоятельств осуществляется посредством постановки и решения соответствующих вопросов в рамках судебно-медицинской экспертизы.

Согласно приводимой методике данные вопросы решаются следующим обра30M.

1. Имелись ли недостатки (дефекты) оказания медицинской помощи в отношении пациента Х., если да, то какие?

Оценка лечебно-диагностического процесса включает в себя квалификацию медицинского вмешательства по 4 основным позициям: 
- обоснованность,

- своевременность,

- техника и условия исполнения,

- полнота [6].

В случае несоблюдения хотя бы одного из 4 критериев, оказанная медицинская помощь квалифицируется как ненадлежащая, то есть имеющая соответствующий недостаток (дефект).

2. Какова степень тяжести вреда здоровью исхода, реализовавшегося у пациента X.?

Степень тяжести вреда здоровью в случаях медицинских правонарушений это разница между имевшимся до медицинского вмешательства состоянием здоровья пациента и после оказания медицинской помощи.

3. Имеется ли прямая причинно-следственная связь между ненадлежащим оказанием медицинской помощи пациенту Х. и возникшим исходом?

Недостаток (дефект), установленный в рамках решения 1-го вопроса, должен быть причиной реализовавшегося исхода. То есть моделирование ситуации без данного недостатка (дефекта) должно обеспечивать невозникновение дальнейшей цепи событий, приведшей к оцениваемому исходу. Учитывая это, согласно описываемой методике, прямая причинно-следственная связь определяется от обратного: «Исключало ли бы надлежащее оказание медицинской помощи наступление имевшегося у пациента Х. исхода?»

Алгоритм методики производства судебно-медицинских экспертных исследований по ятрогенным преступлениям

К сожалению, рассматриваемое направление судебно-медицинских экспертных исследований крайне тяжело поддается унификации, однако упрощенно и сокращенно авторский алгоритм обсуждаемой методики можно представить следующим образом [3] (далее цитата согласно ссылке).

«1. Устанавливаем этиологию и патогенез имевшего место исхода (танатогенез) либо подтверждаем/уточняем их в случае согласия с ранее проведенными экспертными исследованиями.

2. Определяем последний период/этап в этиопатогенезе (развитии) реализовавшегося исхода, когда надлежащее медицинское воздействие достоверно исключало бы (если не рассматривать атипичные случаи) наступление данного исхода, а также имело основание и возможность быть выполненным.

3. В случае если такой период/этап имел место вне лечебно-диагностического процесса, то событие «врачебного» преступления отсутствует. Иными словами, рассматриваемый исход уже предопределен независимо от того будет ли оказана медицинская помощь. Если такой период/этап был в рамках лечебно-диагностического процесса, то определяем лицо, обязанное выполнить соответствующие меры медицинского характера, а также вид и объем последних.

4. Определяем, осуществил ли данный медицинский работник необходимые меры - устанавливаем, допустил ли он недостатки (дефекты) медицинской помощи, либо подтверждаем/уточняем их в случае согласия с ранее проведенными экспертными исследованиями: 
А. Если рассматриваемый медицинский работник необходимые меры не осуществил, то определяем, имел ли он основание и возможность к их выполнению. В случае отсутствия объективных медицинских оснований для указанных мер, профессиональные деяния данного работника не являются ненадлежащими. В случае отсутствия возможности оказания необходимой медицинской помощи устанавливаем, имели ли место уважительные медицинские причины такого бездействия (объективное отсутствие необходимых медицинских сил и средств, болезнь или травма самого врача, оказание в данный момент помощи другому и т.п.). Если таких причин не было, то констатируем прямую (определяющую) причинно-следственную связь между дефектом в виде элемента бездействия и возникшим исходом, при условии, когда в анализируемый период/этап надлежащее медицинское воздействие достоверно исключало бы (если не рассматривать атипичные случаи) наступление реализовавшегося исхода. Иными словами, допущенный недостаток медицинской помощи в виде элемента бездействия закономерно определил наступление неблагоприятного исхода, то есть находится с ним в прямой (определяющей) причинно-следственной связи.

Б. Если рассматриваемый медицинский работник осуществил необходимые меры ненадлежащим образом (учитывая ранее указанные критерии надлежащности), то констатируем прямую (определяющую) причинно-следственную связь между дефектом в виде действия и возникшим исходом, при условии, когда в анализируемый период/этап надлежащее медицинское воздействие достоверно исключало бы (если не рассматривать атипичные случаи) наступление реализовавшегося исхода, за исключением ситуаций с обстоятельствами, исключающими преступность деяния согласно соответствующим статьям гл. 8 УК РФ (причем упор на проверке обстоятельств, исключающих преступность деяния, играет главенствующую роль в этом разделе и делается в обязательном порядке). Иными словами, допущенный недостаток медицинской помощи в виде действия закономерно определил наступление неблагоприятного исхода, то есть находится с ним в прямой (определяющей) причинно-следственной связи.

Перечисленные 4 категории обстоятельств, подлежащих установлению, являются основными, но не исчерпывающими, поэтому в рамках экспертной инициативы в случае необходимости могут решаться и другие вопросы. В ситуациях пролонгированного многоэтапного лечебно-диагностического процесса должны быть дополнительно установлены как минимум еще 2 категории обстоятельств (даже если вопросы по ним напрямую не ставились), так как их определение персонализирует ответственность конкретного медицинского работника:

4. Ненадлежащие меры медицинского характера (и даже полное отсутствие медицинских мер) после окончания периода/этапа, когда последний раз надлежащее медицинское воздействие достоверно исключало бы (если не рассматривать атипичные случаи) наступление реализовавшегося исхода, не состоят в прямой (определяющей) причинно-следственной связи с последним. Обосновывается это тем, что даже надлежащее медицинское воздействие уже достоверно не обеспечивало бы благоприятный исход (при 
этом имевшее место ненадлежащее деяние изолированно могло создавать опасность для здоровья и/или жизни).

5. Ненадлежащие меры медицинского характера (и даже полное отсутствие медицинских мер) до начала периода/этапа, когда последний раз надлежащее медицинское воздействие достоверно исключало бы (если не рассматривать атипичные случаи) наступление реализовавшегося исхода, не состоят в прямой (определяющей) причинно-следственной связи с последним. Обосновывается это тем, что даже ненадлежащее медицинское воздействие (а также полное отсутствие медицинских мер) хоть и может создавать опасность для здоровья и/или жизни, но еще достоверно не определяет наступление имевшего место исхода, так как оставляет пространство вариантов развития иных событий (в том числе за счет последующих этапов медицинской помощи)».

\section{Примеры}

Пример № 1 [3]

«Смерть малолетней П. наступила в 11 часов 45 минут 16 января 2013 года от непосредственной причины в виде острой дыхательной недостаточности, вызванной генерализованной вирусно-бактериальной инфекцией с развитием отека гортани. Последним периодом в развитии данного случая смерти, когда надлежащее медицинское воздействие достоверно исключало бы (если не рассматривать атипичные случаи) наступление реализовавшегося исхода, а также имело возможность и основание быть выполненным, был момент времени с 11 часов 22 минут по 11 часов 30 минут 16 января 2013 года после неудачных попыток интубации врачом вызванной бригады скорой медицинской помощи. Подтвержден недостаток медицинской помощи (дефект) в виде неосуществления необходимых медицинских мер экстренного обеспечения проходимости дыхательных путей (способом коникотомии), допущенный вышеупомянутым врачом. Констатируется наличие прямой причинно-следственной связи между вышеуказанным недостатком медицинской помощи (дефектом) и смертью П., так как надлежащее медицинское воздействие в анализируемый период в условиях крайней необходимости и обоснованного риска (коникотомия) достоверно исключало бы (если не рассматривать атипичные случаи) наступление смерти от острой дыхательной недостаточности. Иными словами, допущенный недостаток медицинской помощи в виде элемента бездействия закономерно определил наступление реализовавшегося исхода по следующей прямой причинноследственной (патогенетической) цепи: возникновение у П. генерализованной вируснобактериальной инфекции $\rightarrow$ развитие отека гортани $\rightarrow$ неосуществление необходимых медицинских мер экстренного обеспечения проходимости дыхательных путей $\rightarrow$ смерть П. от острой дыхательной недостаточности».

\section{Пример № 2 [3]}

«Смерть К. наступила в больнице «Х» в 09 часов 55 минут 09 ноября 2015 года от непосредственной причины в виде отека головного мозга, вызванного прогрессирующей почечной недостаточностью вследствие типичного гемолитико-уремического синдрома, инициированного перенесенной острой смешанной кишечной инфекцией. Лечение имевшейся у К. патологии было симптоматическим (направленным на купирование прогрессирующей почечной недостаточности), так как на сегодняшний момент развития медицины схемы специфической терапии типичного гемолитико-уремического синдрома 
не существует. Констатируется отсутствие значимых недостатков (дефектов) медицинской помощи (небезопасных по своей сути из-за реальной угрозы здоровью и жизни и/ или находящихся в прямой причинно-следственной связи со смертью К.). Проводимые на всех этапах оказания медицинской помощи лечебно-диагностические мероприятия выполнялись в целом надлежащим образом, однако, исходя из сути имевшейся патологии, достоверно не могли исключить наступление имевшего место исхода, реализовавшегося по следующей патогенетической цепи: действие токсинов кишечной и дизентерийной палочек (вследствие перенесенной К. острой смешанной кишечной инфекции) $\rightarrow$ развитие типичного гемолитико-уремического синдрома $\rightarrow$ прогрессирующая почечная недостаточность $\rightarrow$ смерть К. от отека головного мозга».

\section{Пример № 3}

«Смерть Ж. наступила в ГБУЗ «Х» в 8 часов 35 минут 12 апреля 2016 года от непосредственной причины в виде полиорганной недостаточности, вызванной сепсисом вследствие ферментативного перитонита из-за ятрогенной перфорации забрюшинной части общего желчного протока от 31 марта 2016 года.

Подтвержден недостаток (дефект) медицинской помощи в виде перфорации забрюшинной части общего желчного протока (холедоха) в период проведения эндоскопической лечебно-диагностической операции в виде ретроградной холангиопанкреатографии (эндоскопическое вмешательство, позволяющее обнаружить и ликвидировать закупорку желчных протоков) с папиллосфинктеротомией (предрассечение большого дуоденального сосочка) в целях литоэкстракции (удаления камней) от 31 марта 2016 года.

Констатируется наличие прямой причинно-следственной связи между вышеуказанным недостатком (дефектом) медицинской помощи и смертью Ж. Иными словами, недопущение вышеуказанной перфорации исключало бы возникновение каскада осложнений, приведших к смерти Ж. по следующей прямой причинно-следственной (патогенетической) цепи: перфорация забрюшинной части холедоха Ж. в период проведения ретроградной холангиопанкреатографии с папиллосфинктеротомией $\rightarrow$ ферментативный перитонит $\rightarrow$ сепсис $\rightarrow$ смерть от полиорганной недостаточности.

Лечение последствий допущенного дефекта в виде перфорации холедоха уже достоверно не исключало наступление реализовавшегося неблагоприятного исхода. Также согласно современной практике проведения ретроградной холангиопанкреатографии с рубцовым сужением большого дуоденального сосочка требуется предрассечение последнего, которое, по данным литературы, может повлечь вероятное осложнение в виде перфорации холедоха (около $0,5 \%$ случаев).

Решение хирурга о предрассечении большого дуоденального сосочка было обоснованным, так как, несмотря на потенциальную угрозу реализации риска перфорации холедоха, проводимая операция была абсолютно показанной и должна была быть выполнена, иначе закономерно и неизбежно наступила бы смерть Ж., причем избежать этого действиями, не связанными с риском, не представлялось возможным. Иными словами, риск возникновения осложнений медицинского вмешательства достоверно был значительно ниже риска неблагоприятных последствий в случае его непроведения. При всем этом оперирующий хирург должен был предпринять все возможные меры к недопущению событий риска (сведений, свидетельствующих о противоположном, в представленных материалах обнаружено не было). Таким образом, имеются исчерпывающие медицинские признаки обоснованного риска, что, в соответствии со ст. 41 УК РФ, является обстоятельством, исключающим преступность деяния». 


\section{Заключение}

В заключение необходимо отметить, что производство первичных судебно-медицинских экспертиз оказания медицинской помощи собственными экспертными силами ГСУ СК РФ по г. СПб и СУ СК РФ по ЛО нецелесообразно. Данный вид экспертных исследований может назначаться и проводиться на первоначальном этапе расследования в специализированных подразделениях региональных Бюро судебно-медицинской экспертизы Министерства здравоохранения РФ (далее БСМЭ) - в отделах сложных и комиссионных экспертиз. Стоит отметить, что сотрудники данных подразделений БСМЭ большинства регионов достаточно успешно справляются с первичной задачей поиска и нахождения недостатков (дефектов) медицинской помощи. Кроме того, в данных подразделениях по штату предусмотрены должности лаборантов, которые существенно облегчают работу по оформлению исследовательской части заключений.

Накопленный опыт ГСУ СК РФ по г. СПб и СУ СК РФ по ЛО по применению описанного подхода показал его эффективность в течение трехлетнего периода [7] в условиях минимального наличия специалистов (3 действующих сертифицированных судебно-медицинских экспертов), занятых большей частью своей деятельности на судебно-генетическом направлении, один из которых — кандидат медицинских наук, доцент, имеет, помимо высшего медицинского, высшее юридическое образование, а также дополнительную специализацию по специальности «патологическая анатомия», стаж работы по экспертной специальности с 2006 г. (в структуре СК РФ с марта 2014 г.) и опыт руководства Государственным судебномедицинским экспертным учреждением. Два других судебно-медицинских эксперта имеют стаж работы по экспертной специальности с 2008 г. (в структуре СК РФ соответственно с февраля и марта 2016 г.), один из последних также является студентом второго курса магистратуры юридического факультета вуза, второй имеет I квалификационную категорию врача.

\section{Литература}

1. К Кузнецов С. В., Лаврентьев В.П., Селиванов Е.А., Пучков А.А., Плотникова Т. А. Опыт производства собственными экспертными силами ГСУ СК РФ по городу Санкт-Петербургу судебномедицинских экспертиз оказания медицинской помощи в 2014-2016 гг. // История Российского центра судебно-медицинской экспертизы в лицах и фактах, к 85-летию со дня образования: Тр. Всерос. науч.-практ. конф. с междунар. участием. Воронеж: ООО «Издат-Принт», 2017. Т. 1. C. 131-135.

2. К Кузнецов С. В. Порядок организации и производства судебно-медицинских экспертиз оказания медицинской помощи // Медицинское право. 2017. № 3 (73). С. 24-29.

3. Кузнецов С.В. Методика судебно-медицинских экспертных исследований по фактам ненадлежащего оказания медицинской помощи // Мед. право. 2017. № 6 (76). С.35-41.

4. Кузнецов С.В., Селиванов Е.А., Пучков А.А., Лаврентьев В.П., Плотникова Т.А. Трехлетний опыт производства судебно-медицинских экспертиз оказания медицинской помощи собственными экспертными силами Главного следственного управления СК РФ по городу СанктПетербургу // Вест. Акад. Следств. комит. РФ. 2017. № 1 (11). С. 81-83.

5. Варламова Е. А. Некоторые проблемы определения причинно-следственной связи по уголовным делам о ятрогенных преступлениях // Материалы Всерос. науч.-практ. круглого стола: «Проблемы выявления и расследования преступлений в сфере оказания медицинских услуг». М.: Акад. Следственного комит. РФ. 2016. С. 39-43. 
6. Альшевский В.В. Судебно-медицинская экспертиза вреда здоровью в современном уголовном судопроизводстве (процессуальные аспекты, методические принципы и формально-логические алгоритмы). М.: Юрлитинформ, 2004. 176 с.

7. Кузнецов С. В., Пучков А.А., Лаврентьев В.П., Селиванов Е. А., Плотникова Т.А. Возможности выполнения судебно-медицинских экспертиз по «врачебным» уголовным делам собственными экспертными силами Главного следственного управления СК РФ по городу Санкт-Петербургу // Мед. право. 2017. № 4 (74). С. 45-48.

Статья поступила в редакцию 15 ноября 2017 г. Статья рекомендована в печать 31 августа 2018 г.

Контактная информация:

Кузнеиов Семён Валерьевич - канд. мед. наук, доц.; Nachsml@mail.ru

Iatrogenic crimes committed in the field of health care, and a special approach to the production of forensic medical expert research

\section{S. V. Kuznetsov}

Investigation department of the Investigative committee of the Russian Federation in the Leningrad region, 4, Torzhkovskaya ul., St. Petersburg, 197342, Russian Federation

St. Petersburg State Agrarian University,

2, Peterburgskoe shosse, St. Petersburg, 196601, Russian Federation

For citation: Kuznetsov S. V. Iatrogenic crimes committed in the field of health care, and a special approach to the production of forensic medical expert research. Vestnik of Saint Petersburg University. Medicine, 2018, vol. 13, issue 4, pp. 419-429. https://doi.org/10.21638/11701/spbu11.2018.408 (In Russian)

The article presents an integrated approach to the forensic assessment of the medical facts of inadequate medical care. The purpose of the taken out initiative provisions is an increase of efficiency of production of forensic medical examinations of rendering medical care both in the structure of Investigative committee of the Russian Federation and in other judicial and expert institutions including the state. As one of the possible ways to solve this problem is the author's procedure and methods of production of forensic expert research on iatrogenic crimes. On the basis of the stated provisions, possible ways of improving the organisation of forensic activities are proposed. A strong rationale explaining why the structure of the Investigative committee of the Russian Federation when applying for the service in preference to experts with a wide profile (that has two or more related competencies), which can overlap their activities in several areas. Clearly demonstrated that these employees are capable of a comprehensive understanding of the problems lie in the biomedical plane of specialised knowledge, that allows applying the expertise available to the expert on the basis of the official need dictated by a specific investigative task. This approach is successfully used for more than four years in practice in the forensic division of the department of criminology of the Main investigation department of the Investigative committee of the Russian Federation in Saint Petersburg and the division of criminalistics investigation department of the Investigative committee of the Russian Federation in the Leningrad region.

Keywords: forensic examination, disadvantages of medical care, defects of medical care, causation, harm to the health.

\section{References}

1. Kuznetsov S. V., Lavrent'ev V.P., Selivanov E. A., Puchkov A. A., Plotnikova T. A. Opyt proizvodstva sobstvennymi ekspertnymi silami GSU SK RF po gorodu Sankt-Peterburgu sudebno-meditsinskikh 
ekspertiz okazaniia meditsinskoi pomoshchi v 2014-2016 gg. [Experience in the production of its own expert forces of the Main investigation department of the Investigative committee of the Russian Federation in Saint-Petersburg forensic medical care in 2014-2016 years]. Istoriia Rossiiskogo tsentra sudebno-meditsinskoi ekspertizy v litsakh i faktakh, $k$ 85-letiiu so dnia obrazovaniia: Trudy Vserossiiskoi nauchno-prakticheskoi konferentsii s mezhdunarodnym uchastiem [History of the Russian center of forensic medical examination in persons and facts, to the $85^{\text {th }}$ anniversary of the formation: Proceedings of the all-Russian scientific-practical conference with international participation]. Voronezh, OOO «Izdat-Print», 2017, vol. 1, pp. 131-135. (In Russian)

2. Kuznetsov S. V. Poriadok organizatsii i proizvodstva sudebno-meditsinskikh ekspertiz okazaniia meditsinskoi pomoshchi [The procedure for the organization and production of forensic examinations of medical assistance]. Meditsinskoe pravo [Medical law], 2017, no. 3 (73), pp. 24-29. (In Russian)

3. Kuznetsov S. V. Metodika sudebno-meditsinskikh ekspertnykh issledovanii po faktam nenadlezhashchego okazaniia meditsinskoi pomoshchi [Methodology of a forensic medical expert research on the facts of inadequate medical care]. Meditsinskoe pravo [Medical law], 2017, no. 6 (76), pp.35-41. (In Russian)

4. Kuznetsov S. V., Selivanov E. A., Puchkov A.A., Lavrent'ev V.P., Plotnikova T. A. Trekhletnii opyt proizvodstva sudebno-meditsinskikh ekspertiz okazaniia meditsinskoi pomoshchi sobstvennymi ekspertnymi silami Glavnogo sledstvennogo upravleniia SK RF po gorodu Sankt-Peterburgu [Three years of experience in forensic examinations of medical assistance of their own expert the Main investigation department of the Investigative committee of the Russian Federation in Saint-Petersburg]. Vest. Akad. Sledstvennogo komit. RF [Bulletin of The Academy of the Investigative Committee of the Russian Federation], 2017, no. 1 (11), pp. 81-83. (In Russian)

5. Varlamova E. A. Nekotorye problemy opredeleniia prichinno-sledstvennoi sviazi po ugolovnym delam o iatrogennykh prestupleniiakh [Some problems of determining the cause-effect relationship in criminal cases of iatrogenic crimes]. Materialy Vseross. nauch.-praktich. «kruglogo stola»: "Problemy vyiavleniia $i$ rassledovaniia prestuplenii v sfere okazaniia meditsinskikh uslug» [Materials of the all-Russian scientific and practical round table: "Problems of detection and investigation of crimes in the provision of medical services"]. Moscow, Akad. Sledstvennogo komit. RF Publ., 2016, pp.39-43. (In Russian)

6. $\mathrm{Al}$ 'shevskij V.V. Sudebno-meditsinskaia ekspertiza vreda zdorov'iu v sovremennom ugolovnom sudoproizvodstve (protsessual'nye aspekty, metodicheskie printsipy i formal'no-logicheskie algoritmy) [Forensic medical examination of harm to health in modern criminal proceedings (procedural aspects, methodological principles and formal logic algorithms)]. Moscow, Iurlitinform Publ., 2004, 176 p. (In Russian)

7. Kuznetsov S. V., Puchkov A. A., Lavrent'ev V.P., Selivanov E. A., Plotnikova T. A. Vozmozhnosti vypolneniia sudebno-meditsinskikh ekspertiz po «vrachebnym» ugolovnym delam sobstvennymi ekspertnymi silami Glavnogo sledstvennogo upravleniia SK RF po gorodu Sankt-Peterburgu [The possibility of performing forensic examinations on «medical» criminal cases of the private expert forces of the Main investigation department of the Investigative committee of the Russian Federation in Saint-Petersburg]. Meditsinskoe parvo [Medical law], 2017, no. 4 (74), pp. 45-48. (In Russian)

Received: November 15, 2017 Accepted: August 31, 2018

Author's information:

Semyon V.Kuznetsov — PhD, Associate Professor; Nachsml@mail.ru 